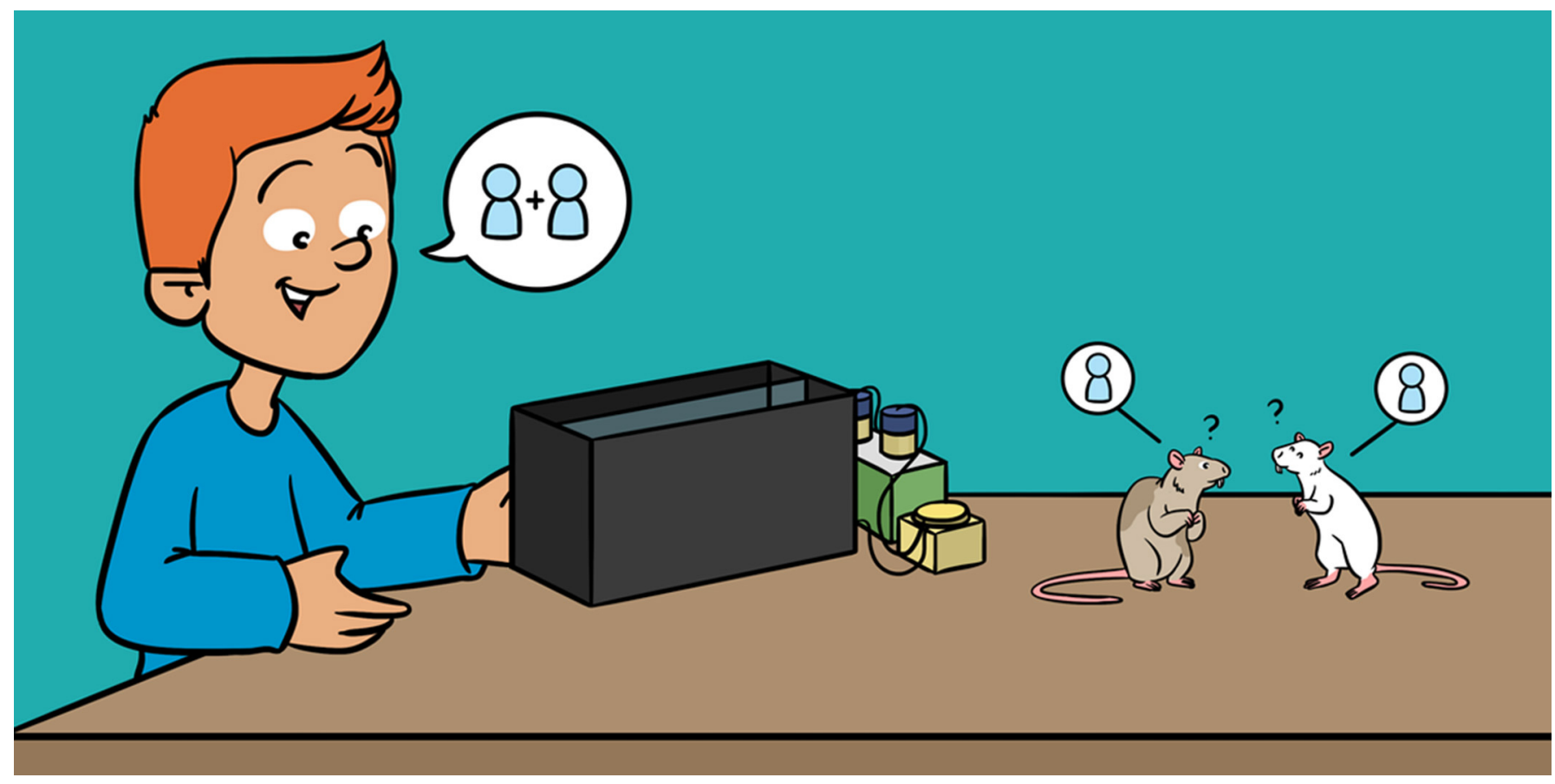

\title{
ARE OUR GENES IMPORTANT FOR COOPERATION?
}

\section{Avi Avital ${ }^{*}$ and Shlomit Aga-Mizrachi}

Behavioral Neurobiology Lab, University of Haifa, Haifa, Israel

YOUNG REVIEWERS:

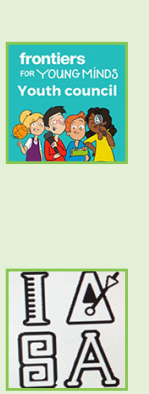

HEBREW

FYM YOUTH

CONCIL

AGES: $15-18$

ISRAEL

ARTS AND

SCIENCE

ACADEMY

AGES: $12-13$

SOCIAL

COOPERATION

The ability to

coordinate and share action toward

mutual goal.
Social cooperation is a state in which people work together on a shared activity from which they both benefit, and the success of each person is dependent on everyone doing their part. Imagine, for example, a basketball game in which all team members make a shared effort and cooperate to win the game. To study this kind of social cooperation in the lab, we used rats. We created a special maze in which two rats must coordinate their behavior as a pair, moving together through the sections of the maze. Using this maze, we found that a rat's genes are more important than its environment in determining its level of social cooperation.

\section{THE IMPORTANCE OF SOCIAL COOPERATION}

Social cooperation is defined as a shared activity in which collaborators benefit not because of their own behavior, but because of the behaviors of all collaborators working together. The collaborators react to one another, and act in ways that support the achievement of the shared goal. In social cooperation, any reward gained is beneficial for all collaborators, but if the group is unsuccessful, the failure is also shared. The rule for social cooperation seems to be, "our strength lies in our unity." 


\section{AUTISM}

A disorder characterized by difficulties with language, communication, and other social skills.

ANIMAL MODEL

Mimicking human normal/abnormal behavior in experimental animal, to enable the understanding of mechanism and enhancing the development of possible treatments.

Social cooperation is vital for human society and can be seen in the daily activities we perform, such as playing together and sharing [1]. Social cooperation is a complex action that requires advanced social and intellectual skills. A disturbance in social cooperation is seen in several disorders, particularly in autism, so it is important for scientists to study the brain's role in social cooperation. Studying skills like social cooperation in humans can be difficult, because humans have a long lifespan, and it is complicated and expensive to do controlled studies that last longer than a few years. In contrast, each rat month is roughly equivalent to 30 human months. Additionally, rat genes are $96 \%$ the same as human genes, rats and humans share many types of behaviors, and rat and human brains are also fairly similar. These characteristics make rats a good animal model to study questions that are too difficult to study directly in humans-like questions about social cooperation!

\section{HOW DID WE ENCOURAGE RATS TO COOPERATE?}

Over the years, scientists have found it difficult to create a good animal model to study social cooperation-mainly because they were unsuccessful at getting the animals they studied, including chimpanzees, elephants, crows, and certain rodents, to cooperate with each other. Therefore, our first challenge was to create a rat model that teaches rats social cooperation and includes a way to measure that cooperation. We created a unique maze that requires social cooperation. The maze is completely automatic and is controlled by video surveillance. In this maze, the two rat participants receive an equal reward when they move in a coordinated way through the parts of the maze.

Our maze is made from a black plastic box divided into two paths by a transparent partition with small holes in it, so that the two rats can communicate without physical contact (Figure 1). The rats must use social cooperation to move together in a coordinated way, from the beginning of the maze path to its end (i.e., from virtual zone A-C). When they reach the end, pumps are automatically activated, giving the rats equal amounts of a sugary liquid as a reward. To get another reward, the rats must repeat their coordinated movement through the maze. Rats practice for 15 min each day, for 18 days. The number of rewards that a pair of rats gets during the 15-min practice each day provides researchers with a measure of their social cooperation [2].

\section{OUR INITIAL FINDINGS}

We discovered several interesting findings through this experiment. First, we found that pairs of rats got higher numbers of rewards compared with a single rat alone in the maze, which tells us that social 
Figure 1

We created a maze to measure social cooperation between pairs of rats. The pair was gradually trained, over 18 days, to coordinate their movements through virtual three areas of the maze $(\mathbf{A}-\mathbf{C})$. Moving through the areas in a coordinated way earned both rats a reward of a sugary liquid. The number of rewards the rats earned was measured during 15 min of practice over each of the 18 days.

\section{GENE}

Consists of nucleotides and serves as the basic unit of heredity leading to a particular characteristic or function.

\section{HEREDITY}

Transfer of genes from parents to their offspring. Genes determine the shared or unique characteristics of each individual.

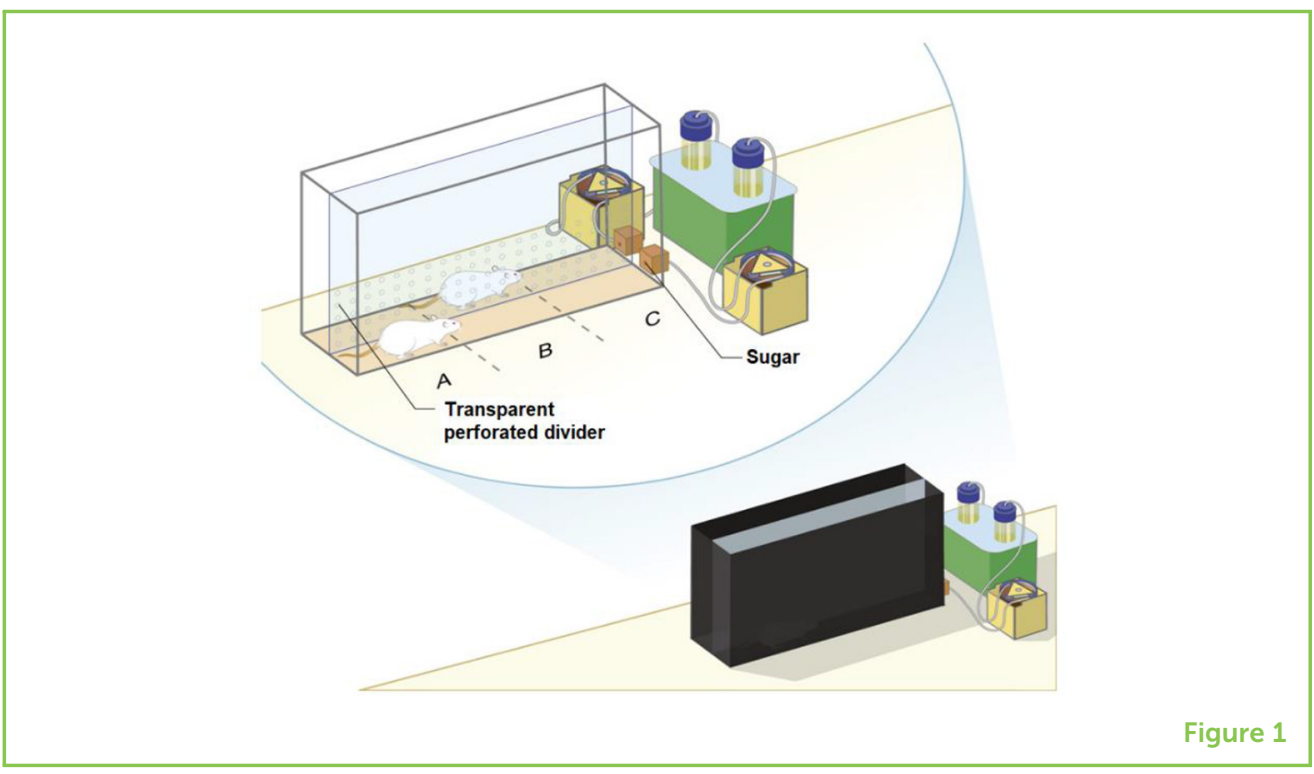

cooperation is a powerful motivator. We also found that decreasing the sweetness of the reward solution did not decrease the number of rewards that the rats achieved. This tells us that the rats were motivated by the social reward rather by the sugary reward. Finally, we found that females earn more rewards than males, meaning they cooperate better. Further, when male and female rats were paired in the maze, they achieved a higher number of rewards than pairs of males, meaning that the female improved the male's social cooperation.

\section{SOCIAL COOPERATION: GENES OR ENVIRONMENT?}

Have you heard the term "nature vs. nurture?" This phrase describes a long-standing controversy in the scientific world, regarding whether human behaviors are determined more by our genes (nature) or by the environment we experience (nurture) [3]. Our genes, which are passed on from our parents, might influence the development and organization of the brain, which could affect our behavior. On the other hand, the external factors in the environment, including exposure to stress, the amount of social support a person has, and other unique life experiences, might also influence behavior. Therefore, as the next stage of our research, we wanted to study whether social cooperation in rats is determined by genes that can be passed on to the rats' offspring. To do this, we created two groups of rats: one group included rats that perform high-level social cooperation, and the other included rats that perform low-level social cooperation.

How did we create these subgroups? We started with adult females and males that were trained in the cooperation maze for 18 straight days. The performance of this generation was analyzed and the rats were grouped into high- or low-performance groups based 
Figure 2

Male and female rats were placed into two subgroups (high performance and low performance) according to the average number of rewards they earned. Males and females from the same group were mated and offspring were tested in the maze for ten generation (F1-F10). In total, we examined 1,052 rats.

\section{VIDEO 1}

Rats from the high performer (A) and low performer group in the social cooperation maze. Notice the social cooperation in group A and a low level of performance in group B.

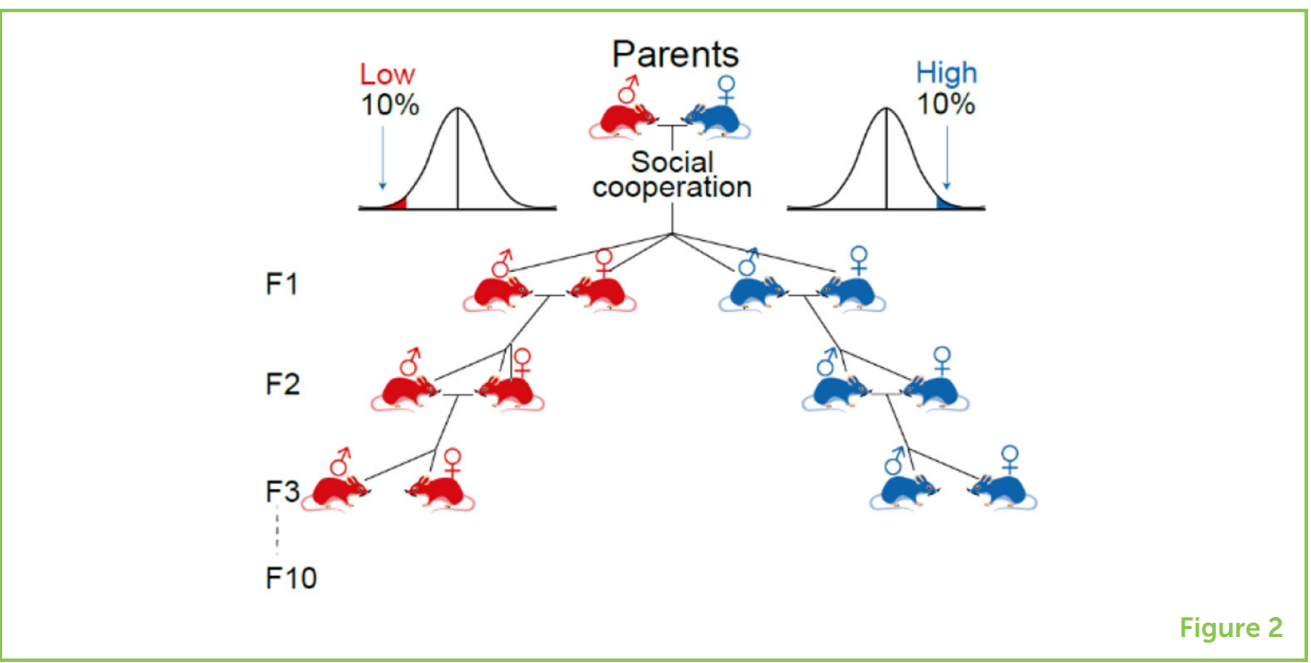

on the average number of rewards they earned. We mated males and females from the high-performance group, and we also mated males and females from the low-performance group. The offspring from both groups were also trained in the social cooperation maze and divided into high- and low-performance groups. We continued selecting the highest- and lowest-performing groups this way, for ten generations (Figure 2). From the fourth generation on, we could see a clear difference between the high and low performers, with social cooperation gradually growing in the high-performing groups over the generations. The low-performing groups kept their initial low level of performance (Video 1).

To make sure this difference in social cooperation was caused by the rats' genes, we examined the number of rewards obtained by the high- and low-performing groups on the first day of testing, for each generation. The number of rewards obtained on the first day must only be due to the genes the rats inherited, since they have not had any previous experience solving the maze using social cooperation. We found that, throughout the course of the experiment, the new generations of high performers gradually increased the social cooperation measured on the first day, while new generations of low performers showed a decrease (Figure 3). This result strongly supports our hypothesis that social cooperation is controlled by genes passed on from the parents, and is not a result of conditions in the environment.

\section{SUMMARY}

Our study showed that the proper research tools and animal models can be used effectively to help scientists understand human behavior. Through our initial studies, we learned that social cooperation is possible to be measured in a rat model and that the social interaction is rewarding more than the sugary reward. By separating rats into 
Figure 3

We studied the social cooperation performance of each new generation of rats. To determine whether genes played an important role in social cooperation, we compared the performance of each generation on the first day they were tested in the maze-when the rats had no learned knowledge of social cooperation. Over the course of the experiment, the new generations of high performers gradually increased their social cooperation on the first day, while new generations of low performers showed a decrease. This told us that social cooperation is based on genes inherited from the parents, and not learned from the environment.

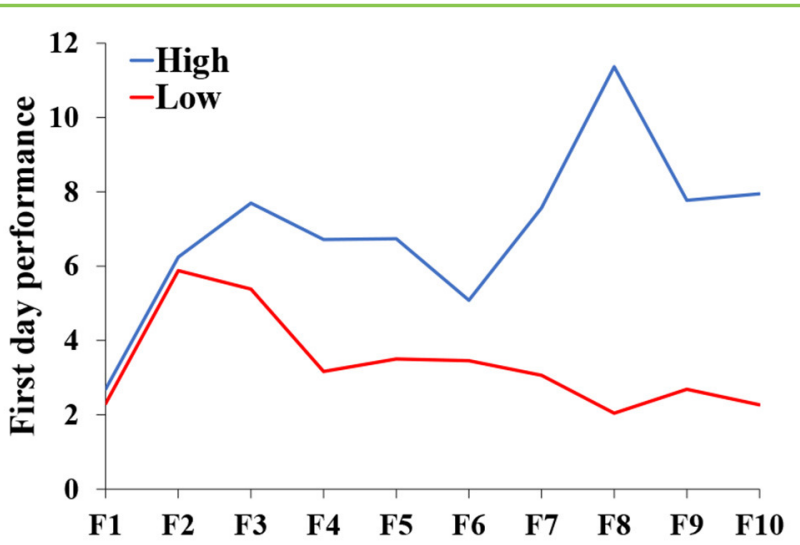

Figure 3

high-performing and low-performing subgroups with regards to their social cooperation, and breeding the rats within those groups for multiple generations, we learned that social cooperation is based on nature (genes) and not on nurture (environment). Hopefully, our research findings will help us to better understand social cooperation in humans and will advance our knowledge of complex disorders such as autism, in which social cooperation is often reduced.

\section{ACKNOWLEDGMENTS}

This research was supported by the Israel Science Foundation (Grant No. 1900/19).

\section{ORIGINAL SOURCE ARTICLE}

Avital, A., Aga-Mizrachi, S., and Zubedat, S. 2016. Evidence for social cooperation in rodents by automated maze. Sci Rep. 6:29517. doi: 10.1038/srep29517

\section{REFERENCES}

1. Tomasello, M., and Vaish, A. 2013. Origins of human cooperation and morality. Annu. Rev. Psychol. 64:231-55. doi: 10.1146/annurev-psych-113011-143812

2. Avital, A., Aga-Mizrachi, S., and Zubedat, S. 2016. Evidence for social cooperation in rodents by automated maze. Sci. Rep. 6:29517. doi: 10.1038/srep29517

3. Moore, D. S. 2003. The Dependent Gene: The Fallacy of 'Nature vs. Nurture'. Available online at:

https://books.google.co.il/books?id=GkMJDdcL7QUC\&pg=PA35\&redir_esc=y (accessed February 8, 2021)

SUBMITTED: 01 August 2021; ACCEPTED: 14 December 2021;

PUBLISHED ONLINE: 17 January 2022. 
frontiers FOR YOUNG MINDS

Youth council
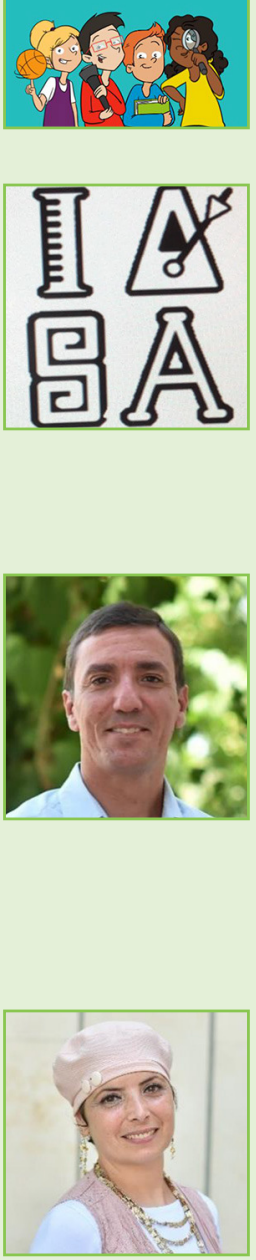

EDITOR: Idan Segev, Hebrew University of Jerusalem, Israel

SCIENCE MENTOR: Idan Segev

CITATION: Avital A and Aga-Mizrachi S (2022) Are Our Genes Important for Cooperation? Front. Young Minds 9:751592. doi: 10.3389/frym.2021.751592

CONFLICT OF INTEREST: The authors declare that the research was conducted in the absence of any commercial or financial relationships that could be construed as a potential conflict of interest.

COPYRIGHT (c) 2022 Avital and Aga-Mizrachi. This is an open-access article distributed under the terms of the Creative Commons Attribution License (CC BY). The use, distribution or reproduction in other forums is permitted, provided the original author(s) and the copyright owner(s) are credited and that the original publication in this journal is cited, in accordance with accepted academic practice. No use, distribution or reproduction is permitted which does not comply with these terms.

\section{YOUNG REVIEWERS}

\section{HEBREW FYM YOUTH CONCIL, AGES: 15-18}

Frontiers for Minds Youth council is a group of teens that joined the Hebrew FYM board. We advise the editorial board on various issues and promote FYM on social media. We reviewed this article with the guidance of Dr. Galia Zer Kavod, the project manager of FYM in Israel.

\section{ISRAEL ARTS AND SCIENCE ACADEMY, AGES: 12-13}

Israel Academy of Sciences and the Arts is a place for curious students who love to learn. In the seventh grade, as part of our elective courses, we are 15 students reading scientific papers that we have chosen. Anat Maoz, our junior high school principal, who also holds a Master's degree in marine biology, leads the course.

\section{AUTHORS}

\section{AVI AVITAL}

I am a professor of neuroscience and head of the Behavioral Neurobiology Lab at the Faculty of Social Welfare and Health Sciences at the University of Haifa. I am interested in studying the effects of emotional, attentional, and social balances during daily activities. I especially enjoy the invention of new research tools and conducting research in both animal models and humans. In my spare time, I drum, grow vegetables in the garden, and enjoy traveling by foot or by off-road vehicle. *Avitalaviahotmail.com

\section{SHLOMIT AGA-MIZRACHI}

I am a doctor of neuroscience, manager of the Behavioral Neurobiology Lab at the Faculty of Social Welfare and Health Sciences at the University of Haifa. I am interested in understanding how the brain influences our behavior and the ways that we can change and shape behavior. I like reading thrillers, cooking new recipes, and messing around with my kids. 